\title{
Does exposure to richer and poorer neighborhoods influence wellbeing?
}

\author{
Donggen Wang ${ }^{1, *}$ \\ Tim Schwanen ${ }^{2}$ \\ Midan Zao ${ }^{1}$ \\ ${ }^{1}$ Department of Geography, Hong Kong Baptist University, Hong Kong \\ ${ }^{2}$ Transport Studies Unit, School of Geography and the Environment, University of \\ Oxford \\ *Corresponding author, email: $\underline{\text { dwang@dgwang @ hbku.ed.hk }}$
}

Accepted for publication in Cities on 12 July 2019

Published as:

Wang, D., Schwanen, T., Mao, Z., 2019. Does exposure to richer and poorer neighborhoods influence wellbeing? Cities 95: 102408. 


\title{
Does exposure to richer and poorer neighborhoods influence
}

\section{wellbeing?}

\begin{abstract}
Geographical differences in wellbeing have attracted increased attention in the science of happiness literature and recent research has become particularly interested in highresolution spatial differentiation within cities. This study contributes to this literature by analyzing the relationships between subjective wellbeing and relative income at the neighborhood level using activity-travel survey data from 2010 in Hong Kong. In contrast to previous studies, the analysis concentrates not only on life satisfaction but also on pleasure derived from daily activities in the city, and considers relative income in people's residential neighborhood and the neighborhoods where they conduct different types of daily activity. The results suggest that social comparisons with regard to income matter to life satisfaction as well as emotional wellbeing, that the effects occur for both the residential neighborhood and the urban places where daily activities are undertaken, and that downward income comparisons tend to have stronger effects on wellbeing than upward comparisons. One theoretical implication that follows from the analysis is that the impact of social comparison in the science of happiness needs to be theorized as dynamic, mobile and contingent upon people's daily trajectories through time and urban space.
\end{abstract}

Keywords: Hong Kong, income, life satisfaction, neighborhood, pleasure, social comparison, wellbeing 


\section{Does exposure to richer and poorer neighborhoods influence wellbeing?}

\section{Introduction}

There is a long tradition of research in Geography and Urban Studies about the nature of wellbeing and the good life in the city. Ballas (2013) has summarized the debates, noticing that these have been influenced deeply by the rise of the 'science of happiness' (Diener, 2000 ) in the $21^{\text {st }}$ century. This science has long considered the role of geography by looking at differences between countries, regions or cities (e.g. Easterlin, 1995; Oswald and Wu, 2010; Okulicz-Kozaryn, 2015, 2017) but has become increasingly interested in highresolution geographical differences in wellbeing within cities (e.g. White et al., 2013; AlaMantila et al., 2018).

The happiness literature highlights the importance and challenge of correctly specifying hypothesized effects of space - that is, the broader urban context - and place, or the specific site where an individual is or an activity is undertaken, on subjective wellbeing. In addition to having direct effects, characteristics of place and space are thought to mediate and mold the effects of non-spatial factors, such as life circumstances, on wellbeing. For instance, the associations between individuals' income and their subjectively experienced wellbeing have repeatedly been shown to be contingent upon income levels in the area in which

people reside (e.g. Luttmer, 2005; Clark et al., 2009; White et al., 2013). The theoretical 
implication of such results is that effects of social comparison on subjective wellbeing are often spatial in nature - a point recognized more than fifteen years ago by Pacione (2003, page 19) when he wrote that a geographical approach to wellbeing should consider the relationship between people and their everyday living environment and analyze 'the degree of congruence or dissonance between city dwellers and their urban surroundings'.

While previous research has suggested that space and place shape wellbeing in multiple ways, it has arguably also underappreciated how the effects of space and place on wellbeing are embedded in everyday activities and the different urban environments in which these unfold (Schwanen and Wang, 2014). To an extent this reflects an overreliance on secondary data containing only generic indicators of wellbeing (e.g. measures of satisfaction with life or general happiness) and on low-resolution spatial information at the level of countries, counties or municipalities. Nonetheless, the under-appreciation also reflects a static approach in which only attributes of space and place that are defined solely on the basis of individuals' residential address are correlated with quantitative measures of their subjective wellbeing. However, work on the 'uncertain geographical context problem' (UGCoP) (Kwan, 2012) suggests that the residential location is not necessarily the correct or most important geographical context that affects behavior and experience, especially if people spend much time away from where they reside.

The current study uses primary data from a sample of Hong Kong residents to analyze how individuals' subjective wellbeing differs according to their household income relative to that of their neighbors and the people they encounter in daily urban life. It extends previous 
studies on social comparison effects of income on subjective wellbeing in four ways. First, and following concerns about the UCGoP, we complicate the notion of the reference group in social comparison by not only defining this at a spatially disaggregated scale but also moving beyond a focus on the residential neighborhood to consider places where everyday activities, such as paid employment, shopping and recreation are undertaken. Second, whereas previous studies have been limited to a focus on life satisfaction or overall happiness, the current study considers both longer-term satisfaction with life and assessment of short-term emotional wellbeing. Since the income effects on wellbeing can be quite different for life satisfaction and short-term, activity episode-level emotional wellbeing (Kahneman and Deaton, 2010), it can reasonably be expected that the social comparison effects of income will also differ between them; further study is thus needed. Third, in considering differences in life satisfaction and emotional wellbeing according to relative income, the analysis below allows for asymmetry and non-linearity in the effects of upward and downward comparison with respect to income. Finally, rather than using data from a sample of different cities as in most earlier studies (e.g. Luttmer, 2005; Clark et al., 2009; Asadullah et al., 2018), this study relies on data from a single city, Hong Kong. The use of data from different cities is potentially problematic as there are significant variations in wellbeing between cities, while city-related factors such as climate, geography, and social norms may conceal or obscure the relationship between relative income and wellbeing (Oishi, et al., 2011).

The next section reviews existing studies on the impacts of space, place and income on subjective wellbeing, and presents the conceptual framework for this study. Section 3 
introduces the study design, data and methods used. In section 4 we report the findings. The last section concludes the paper and discusses implications of the analysis.

\section{Wellbeing, geography and income: review and framework}

\subsection{Understanding and measuring wellbeing}

Wellbeing is a term that is widely used but often poorly defined, and it is often utilized interchangeably with happiness and quality of life. Debates on the conceptualization of wellbeing go back to at least Classic Antiquity and multiple conceptualizations continue to co-exist today (e.g. Ballas, 2013; Nordbakke and Schwanen, 2014). Nonetheless, the idea at the heart of the science of happiness literature that wellbeing is a measurable, objectively knowable state that inheres in individuals has become very influential, also in Geography and Urban Studies. Yet, different understandings of subjective wellbeing continue to exist within the science of happiness literature. Three prevalent approaches consider wellbeing in terms of fulfillment of desire (preference satisfaction), flourishing and the realization of people's full potential (eudaimonic approaches), and evaluations of how people feel (hedonic approaches) (Ballas, 2013; Nordbakke and Schwanen, 2014). Within the latter, a distinction can be made between on the one hand more reflective, long-term oriented evaluations of how satisfied with life or happy people are and on the other hand more affective, short-term evaluations of pleasure and pain - henceforth called emotional wellbeing (Kahneman et al., 2006; Schwanen and Wang, 2014). Empirical research has 
shown that this distinction matters insofar that inter-personal differences between life satisfaction and emotional wellbeing are correlated with different factors and conditions (ibid.). However, quantitative studies of spatial differences in wellbeing remain heavily skewed towards the use of long-term oriented measures of how satisfied with life or happy people are.

\subsection{Wellbeing, place and space}

Within the science of happiness literature, research on spatial differences in wellbeing continues to privilege higher levels of spatial aggregation such as the national, regional or city level (e.g. Oswald and Wu, 2010; Aslam and Corrado, 2013; Helliwell et al., 2016). Even debates in Urban Studies about whether people are less happy in cities in general and in bigger and denser cities in particular (e.g. Berry and Okulicz-Kozaryn, 2011; Jiang et al., 2011; Florida et al., 2013; Chen et al., 2015; Okulicz-Kozaryn, 2015, 2017; Sun et al., 2016; Wu and Li, 2017; Lee et al., 2018) tend to be conducted for the most part on the basis of low-resolution spatial data about where people live.

Research is nonetheless moving towards examining geographical differences in wellbeing at greater spatial resolutions, with a specific focus on differentiations within cities. This is in part owing to the often sharp socio-economic inequalities and differences in life conditions in cities, yet also because wellbeing often varies over short metric distances within urban areas. Wang and Wang (2016) use self-collected survey data to show that 9\% of differences in life satisfaction across Beijing is due to district-level factors. In addition 
to differences in socio-economic status (Dittmann and Goebel, 2010; Ludwig et al., 2012), unemployment levels, crime rates and safety, maintenance, air pollution, population density, access to facilities (e.g. schools, healthcare, retail, public transport) and green space, and travel conditions have been shown to be correlated with neighborhood-level differences in wellbeing (e.g. MacKerron and Mourato, 2009; Arifwidodo and Perera, 2011; Morrison, 2011; Ballas and Tranmer, 2012; Gandelman et al., 2012; White et al., 2013; Li and Kanazawa, 2016; Ala-Mantila et al., 2018).

Studies have also looked specifically at neighborhood-level factors in Chinese cities. As in their Western counterparts, both physical and social environment attributes such as land use, travel conditions, proximity to urban parks, safety and neighborhood social capital are correlated with wellbeing in Chinese cities (Liu et al., 2016; Dong and Qin, 2017; Ma et al., 2018; Zhang and Zhang, 2018). Empirical studies devote specific attention to the impact of neighborhood environment for rural-to-urban migrants because their wellbeing is consistently found to be lower than that of city residents by birth and may depend in specific ways on the local geographical context (Wen and Wang, 2009; Knight and Gunatilaka, 2010; Liu et al., 2017). For example, Liu et al. (2017) show that neighborhoodlevel social capital and deprivation influence the life satisfaction of migrants in Guangzhou but not their emotional wellbeing (measured using the Positive and Negative Affect Schedule); physical aspects such as neighborhood cleanliness and amenities show no significant influence on migrants' subjective wellbeing. 
Studies of neighborhood-level variations in subjective wellbeing rely heavily on the measurement of life satisfaction. One recent study that analyzes short-term emotional wellbeing is Birenboim's (2018), which uses ecological momentary assessment among 91 students in Jerusalem. He shows that momentary experiences of happiness, annoyance, comfort and security vary more with place and situational characteristics, such as where participants were (home, office, mall, transportation, etc.) and what they did and with whom, than with socio-economic or personality factors. Birenboim's results indicate the importance of extending the analysis of spatially disaggregated variations in wellbeing beyond a focus on life satisfaction.

\subsection{Wellbeing and income}

Another way in which neighborhood-level analysis of subjective wellbeing can be extended is by considering how neighborhood factors interact with variations in wellbeing according to non-spatial factors. There is a long history of research considering how geographical context at the country level mediates the relationship between income and wellbeing ever since the first publications on the 'Easterlin paradox' (Easterlin, 1974, 1995; see also Veenhoven and Hagerty, 2006; Jebb et al., 2018). ${ }^{1}$ This research is part of a broader literature about the relationship between income and wellbeing at different levels

\footnotetext{
${ }^{1}$ The Easterlin paradox concerns the relationship between economic development and quality of growth and has been reformulated over time. The original version held that average happiness did not depend on a country's log-income per capita and that rises in that income in a given country did not generate similar rises in average happiness (Easterlin, 1974). This version was later adapted after many studies had shown clear cross-sectional correlations between a country's income per capita and average happiness, but Easterlin (1995) maintained that average happiness had not increased over time notwithstanding increased economic development.
} 
of spatial aggregation. While numerous studies across countries, regions, societies and social groups have shown individuals in higher-income households to be happier than those in lower-income households (e.g. Cummins, 2000; Aknin et al., 2009), there is much less consensus concerning the detailed effects of income on wellbeing. Differences in conclusions in part reflect differences in whether analysis is cross-sectional or longitudinal, which spatial scale is considered, whether the focus is on absolute or relative income, and which aspect of wellbeing is considered. Cutting across these differences in research design is the possibility that any relationship between wellbeing and income differs across geographical contexts rather than being universal ('law-like') in character. As the current study is concerned with intra-urban variations in wellbeing and very few studies at this scale adopt a longitudinal approach to analysis, the remainder of this section concentrates on the absolute/relative income and definition of wellbeing issues.

\subsubsection{Relative income}

There is a debate about whether relative income - whether people have more or less income than others ${ }^{2}-$ is as strongly correlated with subjective wellbeing as absolute income is (for overviews, see Clark et al., 2008; Yeung and Lucas, 2016). Effects of relative income are widely assumed to result from social comparisons. Festinger (1954) suggested that people are most likely to compare themselves to others who are proximate and similar, which is

\footnotetext{
${ }^{2}$ Relative income is sometimes also defined longitudinally as individuals' income at a particular moment in time vis-à-vis their own income at some point in the past or in the future (e.g. Diener et al., 1993; Clark et al., Knight et al., 2009; Asadullah et al., 2018). Since the current study uses cross-sectional data only, these understandings are not considered here.
} 
usually known as the 'keeping up with the Joneses' phenomenon. The social comparison perspective on subjective wellbeing therefore holds that individuals' subjective wellbeing depends on how they compare with their peers or neighbors in terms of life circumstances, including their income. It implies that people's income, and possibly the activities and purchases it enables, are at least to some extent 'positional goods' (Frank, 2008; Ballas, 2013), the evaluation of which - as manifested in stated levels of life satisfaction, for instance - depends on their context rather than (only) on their inherent properties.

Specifically, it has been suggested that downward comparison - i.e. comparing oneself to others who are worse off for the item of comparison - may make individuals happy, while upward comparison to others who are better off may make them miserable (Wills, 1981). Different principles for comparison have also been identified. Parducci (1968) has proposed that people usually compare with others according to range-frequency principles. In the former case individuals compare their own value (e.g. income) with the range (i.e., the minimum and maximum levels of income) in the reference group. In contrast, the frequency principle suggests that the comparison is based on the relative position of an individual in the reference group in terms of income or another life circumstance (Hagerty, 2000). Nonetheless, in empirical studies of relative income the mean or median for the reference group is typically used, possibly because this is easier to ascertain than the range or people's relative position (although see Boyce et al., 2010). An important distinction in this regard is whether perceived relative income - people's subjective ranking of their income vis-à-vis a reference group - or their actual income relative to that group is considered; Cheung and Lucas (2016) suggest that evidence supporting comparison effects 
with respect to actual relative income on subjective wellbeing is more mixed than for perceived relative income.

As for with whom people compare themselves, Goethals and Klein (2000) indicate that the reference group usually comprises people with similar attributes. In studies of relative income and wellbeing, reference groups consisting of other individuals have been defined in two main ways: on the basis of social relationships, as when colleagues or relatives are considered (e.g. Clark and Senik, 2010), or on the basis of physical proximity or metric distance. Various spatial scales have been deployed in geographical definitions of the reference group, from the country (Caporale et al., 2009; Gokdemir and Dumludag, 2012) or province in Canada (Latif, 2016), via intermediate scales such as the county level in the USA (Diener et al., 1993; Cheung and Lucas, 2016) and the city and county level in China (Huang et al., 2016; Asadullah et al., 2018), to the local level. The latter still covers a considerable range of spatial scales and area sizes, from the Public Use Microdata Area (PUMA - a spatial unit used for survey purposes in the United States with $\pm 150,000$ inhabitants on average) used in Luttmer (2005), to the 'villages' in rural China (Knight et al., 2009) or statistical area units known as the 'Middle Layer Super Output Areas' (MSOAs, median population: 7200) and the Local Super Output Areas (LSOA, median population 1,500) in the UK (Albor et al., 2014; White et al., 2013). Others have defined their own neighborhoods, including Clark et al. (2009) who have divided Denmark into around 9,000 neighborhoods with at least 150 residents each. While there is considerable variation in terms of the spatial scale at which the reference group is identified in studies of the relationship between relative income and wellbeing, the assumption always seems 
to be that the reference group should be defined on the basis of people's residential location. This is potentially problematic when high-resolution spatial data are used, given that most people tend to spend much time away from their homes as part of their everyday activities.

Results regarding the relationship of wellbeing with reference income, defined in terms of the local average income or the reference group's income, or the relative income, which directly compares or ranks people's income with or vis-à-vis that of their peers, differ across studies. Negative correlations between reference income and satisfaction are the most common finding and can be observed for reference groups defined at different geographical scales (e.g. Luttmer, 2005; Clark et al., 2008; Caporale et al., 2009; Gokdemir and Dumludag, 2012; Cheung and Lucas, 2016; Huang et al., 2016; Latif, 2016). Negative correlations are also consistent with the idea that upward comparison of incomes reduces happiness, while downward comparison makes people happier. Luttmer (2005), for instance, found that higher earnings of neighbors at the PUMA level were associated with lower happiness, an association that effect was stronger for individuals who socialized more in their neighborhoods.

Other studies could not detect statistically significant effects of reference income at the county or metropolitan level in the USA (Diener et al., 1993; Hagerty, 2000) or the LSOA level in the UK (White et al., 2013). Hagerty (2000) found that simply using the mean income for the reference group was insufficient to identify statistically significant differences in happiness. This was only possible if information on the range and frequency of incomes across the metropolitan area was introduced in the analysis. Albor et al. (2014) 
found that there can be mental health benefits (i.e., lower odds of depression or anxiety) for high educational and occupational status mothers living in socio-economic congruity with their LSOA area but that this congruity effect was not significant for low-status mothers. In contrast, Clark et al. (2009) found that reference income at the neighborhood level in Denmark had a positive effect on life satisfaction. This, they suggest, may reflect the existence of valued local public goods such as greater social capital and less crime or anti-social behavior in richer neighborhoods.

Wellbeing research has also considered relative income through either a focus on people's position in a rank order of income or a direct comparison of their income to that of the reference group. Using the British Household Panel Survey, Boyce et al. (2010) demonstrate that the effect of individuals' ranked income (i.e. their relative position when surveyed individuals are ranked from high to low income) trumped that of both absolute and reference income in regression models of life satisfaction. Clark et al. (2009) also report a strong ranked income effect at the small neighborhood level in Denmark. Latif (2016) adopts a different approach by regressing happiness on the difference between a person's household income and the reference group's income and on a whole series of other variables. The effect of the difference variable is positive and statistically significant, suggesting not only that downward (upward) comparison is associated with greater (smaller) happiness but that the difference in happiness increases when then income difference is larger. Asadullah et al. (2018) also find lower happiness when people's income is below the city average in China, and the reduction in happiness increases the gap between personal and city income is larger; they do not consider downward comparisons 
in income. In their study of villages in China, Knight et al. (2009) do consider upward and downward comparisons and find clear evidence of asymmetrical effects: the reduction in happiness if people's household income is much below the village average is more than three times as large as the increase of their income is much above that average. Upward comparison may also weigh more heavily than downward comparison in other contexts.

\subsubsection{Dimensions of wellbeing}

Kahneman and colleagues have argued that the effects of (absolute) income on long-term oriented evaluations of life satisfaction may be larger than on short-term oriented emotional wellbeing because questions about life satisfaction can disproportionally focus people's minds on their material wellbeing and shift attention away from how people use their time (Kahneman et al., 2006; Kahneman and Deaton, 2010). Using US data, Kahneman and Deaton (2010) showed divergent effects of income on a measure of life satisfaction and indicators of emotional wellbeing, While the former was linearly related with log-income, the latter only rose with income up to a threshold (US\$75,000 in their study). They concluded that low income was associated with low life satisfaction and prevalence of negative emotions, whereas high income only brought great satisfaction with life to a limited extent. Recently, Stone et al. (2018) have used the American Time Use Survey to examine the relationships between emotional wellbeing and income. They found that income has little or no bearing on the extent to which people feel happy, tired or stressed as part of their daily activities; however, the prevalence of pain and sadness were negatively correlated with income. In Birenboim's (2018) self-collected data among students in 
Jerusalem there were also no statistically significant differences in momentary experiences of happiness, annoyance, comfort or insecurity according to income. However, to the best of our knowledge, the effect of relative income on short-term emotional wellbeing has not yet been examined.

\subsection{Conceptual framework}

How is people's life satisfaction affected by living and spending time in neighborhoods where the income is different from their own? Will people experience more or less pleasure when they frequent places as part of daily urban life where they are better or worse off than the average others? Based on the literature review and theoretical discussion presented above, a conceptual framework for answering these questions is depicted in Figure 1.

[Insert Figure 1 here]

First, the framework distinguishes between life satisfaction as a long-term oriented, general indicator of subjective wellbeing and episode-level emotional wellbeing at the level of daily activities. Accordingly, Figure 1 contains two parts and directions attention the question whether the nature and strength of social comparison effects of income differ between these two dimensions of wellbeing.

Second, the framework recognizes the need for further research into high-resolution spatial differences in wellbeing in general and neighborhood-level studies of the relationship 
between relative income and wellbeing in particular. Specifically, life satisfaction is hypothesized to be affected by not only individuals' life circumstances but also by neighborhood-level attributes (e.g., accessibility, population density) of their residential location. Furthermore, in considering life satisfaction the current study moves beyond a focus on people's residential location only and adopt a more dynamic orientation by considering the different neighborhoods people frequent as part of their daily activities. Similarly, episode-level emotional wellbeing of daily activities is hypothesized to be affected by neighborhood-level attributes of their activity locations, in addition to life circumstances and activity episode attributes (e.g., activity type, timing, company). In this way the study also sheds light on the potential significance of the UGCoP in research on the association between relative income and wellbeing.

Moreover, the reference group is defined at a spatially disaggregated scale, and the distinction between reference and relative income is recognized at the neighborhood level in this study. The potential effect of neighborhood reference income on wellbeing will be explored, and relative income - whether people have more or less income than others in the neighborhood - will be included to examine social comparison effects of income. This also allows the question whether the effects of upward and downward income comparisons on wellbeing differ from each to be explored.

\section{Study Design}




\subsection{Data and sample}

The data used for the study are derived from an activity and time use diary collected in Hong Kong in July-November 2010. The diary traced individuals' paths through space and time continuously over a one-day period starting at 3:00 AM. Participants were asked to identify activity and travel episodes. For activity episodes they had to record the starting and ending time, the type of activity undertaken (18 categories), and the location and which and with whom (company) the activity was undertaken. For travel episodes, information on starting and ending time and transport mode was collected. Following the day reconstruction method (DRM) approach (Kahneman et al. 2006), questions about emotional well-being were asked for each activity and travel episode. These questions were based on the core affect approach developed by Russell (1980, 2003). The core affect approach measures the basic affective qualities of any emotional experience along two dimensions called valence and activation. Two single items with seven categories (from very unpleasant to very pleasant and from not active at all to very active) were included in the time-space diary to capture core affects for each activity and travel episode. As for life satisfaction, a single question "Taking all things together, how satisfied are you with your life as a whole?" with five response categories (from not at all satisfied to very satisfied) was included to obtain information on overall life satisfaction. For more details on the measures of wellbeing of this survey, readers are referred to Schwanen and Wang (2014).

[Insert Figure 2 here] 
The geographic distribution of the respondents is illustrated in Figure 2, as well as the median monthly household income of their residential areas (based on DCCAs, see below). As one of the most affluent cities in the world, Hong Kong is facing serious income disparities, which have also been reflected in the spatial residential pattern (DeLang and Lung, 2010). Studies have identified spatial concentrations of poverty in both inner-city (the dash line circle) and suburban areas of Hong Kong (Figure 2). Their existence can be related to the population decentralization into the New Territories and also the public housing policies in Hong Kong (e.g., DeLang and Lung, 2010; Monkkonen and Zhang, 2011, Guo et al., 2018).

A total of 1,500 individuals were recruited to participate in the study through cold calls to telephone numbers randomly selected from a large database obtained from a local telecommunication company. They were invited to fill in the diary and provide other related information online. A cash coupon of $\mathrm{HK} \$ 50$ was offered for each completed questionnaire. In the end 770 individuals (51.3 percent) filled out the online survey completely. The sample resembles the Hong Kong population in terms of employment status, housing type, and car ownership, although the young and unmarried, women, the higher educated and those on a higher income are over-represented in the sample. Women account for $58.4 \%$ of the sample and $51.4 \%$ of the respondents at the age of 15 or older have a university education or above. Both percentages are higher than those of the general population, which are $53.4 \%$ and $27.0 \%$, respectively. On the other hand, seniors are underrepresented in the sample: individuals aged 50 or older account for $15.8 \%$ of the sample, whilst their share in the general population is $34.0 \%$. The sample represents the 
general population quite well in terms of car ownership: 18.9\% of sample households own private cars, against $17.8 \%$ in the general population (calculated from CSDHK, 2011).

Secondary data on the neighborhood-level attributes of individuals' residential and activity locations were also collected. The 2011 Hong Kong Population Census provides social, demographic and economic data at the level of District Council Constituency Area (DCCA), which is comparable in size to the U.S. census tract. In 2011, Hong Kong was divided into 412 DCCAs under 18 districts. A neighborhood in the present study refers to one or several DCCAs, depending on the size of the DCCAs and if the commonly used name of the area covered several DCCAs. In cases where a neighborhood covers several DCCAs, we have aggregated the DCCA-based into neighborhood-based data.

\subsection{Variables}

Three groups of variables are correlated with life satisfaction and emotional wellbeing. The first group concerns variables characterizing the neighborhoods of homes and activity sites. They include the median monthly household income, percentage of older adults (aged $\geq 65$ ), percentage of public rental housing, percentage of people with tertiary education or higher, the proportion of employed adults who work and live in the same district, and population density. Information on these variables was derived from the 2011 Hong Kong population census. A variable measuring accessibility, or the relative ease with which potential destinations can be reached, was also added. This is a gravity-based measure, defined as 
$A_{i}=\sum_{j} \frac{P_{j}}{D_{i j}}$, where $i$ and $j$ are spatial units; $P j$ is the population size of unit $j$; and Dij the straight-line distance between $\mathrm{i}$ and $\mathrm{j}$.

To capture the effects of neighbors' income on life satisfaction and emotional wellbeing, we include not only the median income for the neighborhood where respondents live as indicator of reference income but also multiple relative income variables. The latter measure the differences between respondents' household income and the median actual household income of their residential neighborhood or the neighborhood where they undertake a particular activity episode. Instead of a continuous indicator of difference (as in Latif, 2016), we assume that people rely on simplified, binary representations of difference - i.e. income is substantially higher or lower than that which is common in the neighborhood - when making social comparisons. We tested different thresholds of difference during the empirical analysis and found that $\mathrm{HK} \$ 3,000$ provides the clearest and most robust results. This value amounts to $1 / 6$ of the median monthly household in Hong Kong at the time when the data was collected (CSDHK, 2011) and is almost half of the mean value of HK\$6,800 with which respondents' household income exceeded the median income in their residential neighborhood in our sample (see Table 1).

The second group of variables measure various dimensions of activity episodes: starting time, duration, activity type and company. Four activity types are distinguished: activities at home (including sleeping, personal care, housework, care-giving, leisure, etc.); work activities (including paid employment and education); maintenance activities (including shopping, errands, and personal affairs outside the home); and recreation (including visits 
to parks, sports grounds, places of entertainment, food premises, and the homes of friends or relatives).

The last group of variables concerns individuals' life circumstances. They include age, gender, marital status, education attainment, monthly household income, household size, possession of a driver's license, presence of children ( $<12$ years old) and older adults (aged $\geq 65$ ), car ownership, and housing type (whether or not in public rental housing provided by the government). The selection was based on the science of happiness literature and the authors' earlier research (Schwanen and Wang, 2014).

\section{Findings}

\subsection{Initial analysis of the relationship between income and wellbeing}

We first present the results of some descriptive analyses of the link between relative income and life satisfaction. Table 1 reports the differences between respondents' monthly household income and the median monthly household income of their residential neighborhoods according to level of life satisfaction for the entire sample and for different gender and age groups. Although the number of respondents who are not or not at all satisfied with their life is (very) small, it is evident that the level of satisfaction tends to increase with the extent to which people's income is greater than the median income of their residential neighborhood. Being richer than one's neighbors is associated with being 
(very) satisfied with life, whereas being poorer tends to be linked to dissatisfaction with life. Table 1 does not suggest that the nature or size of the effects on life satisfaction differs between downward and upward income comparison. These observations apply not only to the entire sample, but also to a large extent to the different gender and age groups.

[Insert Table 1 here]

Table 2 presents levels of life satisfaction against the average difference between respondents' monthly income and the duration-weighted average median monthly household income of the neighborhoods covered by the activity spaces of the respondents concerned. Following the transport studies literature (e.g. Schönfelder and Axhausen, 2003; Wang et al., 2012), the activity space covers the places where a respondent spent time on the day of data collection. They include places for home, work, shopping, recreation, and other activities. These places may be dispersed across the city and a respondent often spends different amount of time at different places. So, here the reference household income is the average of the median household incomes of all the neighborhoods covered by a respondent's activity space, weighted by the amount of time that they spent in each of the neighborhood on the diary day. The results for the out-of-home activity space (i.e., the activity space excluding home) are presented in the last column of Table 2. The two measures in Table 2 offer more precise and dynamic indicators of people's exposure to geographical context than that in Table 1 and therefore reduce the risk of findings being confounded by the UGCoP (Kwan, 2012). 
The conclusions remain broadly similar, with life satisfaction being higher as respondents' household income to a greater extent exceeds the median income in the areas where they spent time on the survey day. The main difference with Table 1 is that the effects of downward income comparison seem to be larger than those for downward comparison when the reference neighborhood is defined on the basis of where people actually spend time. This difference is particularly pronounced if only out-of-home activities are considered. However, given the small number of participants $(n=70)$ who were dissatisfied or very dissatisfied with life, only tentative conclusions about upward income comparisons can be drawn from a comparison between Tables 1 and 2 .

[Insert Tables 2 and 3 here]

The relationship between relative income and emotional wellbeing at the activity episode level is much less obvious than for life satisfaction. When the valence dimension is considered (Table 3), a positive association between income difference and episode emotional wellbeing can be observed for in-home activities when the highest and lowest valences values (very unpleasant, very pleasant) are disregarded. For work activities and to a lesser extent for recreation, a positive association exists within the range from somewhat unpleasant to somewhat pleasant, but not for more intense experiences of pleasure or displeasure. For shopping activities, there is no evidence for a clear relationship between relative income and pleasure derived from the activity.

\subsection{Modeling the relationships between income and wellbeing}




\subsubsection{Life satisfaction}

Since life satisfaction is measured on the ordinal scale, ordered logit models have been developed to examine the relationship between income and wellbeing in greater depth. Table 3 presents three models with identical independent variables, except for the income variables. Model A includes respondents' household income and a reference income variable reflecting the median household income in the residential neighborhood, whereas Model B incorporates only relative income variables in which respondents' household income is contrasted to the median household income of the residential neighborhood and to the duration-weighted mean of the median household incomes of the neighborhoods where respondents conducted activities on the survey day. Model C is identical to Model B, except for the addition of respondents' absolute household income.

While the model fit is low across all models, the goodness-of-fit indicators do indicate that the use of relative income, instead of absolute and reference income, significantly improves the model fit (Chi-square: 10.7, $\mathrm{df}=1, p=0.0011$ ). Model C similarly outperforms Model A (Chi-square $=15.4, \mathrm{df}=3, p=0.0015$ ) and is only marginally better than B and merely at the $90 \%$ confidence level (Chi-square $=4.7, \mathrm{df}=2, p=0.0954$ ). In other words, a model with absolute household income plus relative income variables offers the best statistical explanation of variations in life satisfaction within our sample. 
In model $\mathrm{A}$, the income variables have signs that support the reference income hypothesis. For respondents in households with an income over $\mathrm{HK} \$ 40,000$, life satisfaction tends to be one or two classes (1.5 point on a five-point scale) above that for respondents with household income up to $\mathrm{HK} \$ 20,000$. Nonetheless, this income effect is much stronger than that of the reference income of the residential neighborhood, given that a $\operatorname{HK} \$ 20,000$ increase in the latter only corresponds to a reduction in life satisfaction by 0.17 point.

The significance of relative income effects is evident from Model B, which allows for nonlinearity and asymmetry in social comparison. The model shows that the average life satisfaction is 0.8 point - almost one ordinal class - higher among respondents whose monthly household income is more than HK\$3,000 (around US\$385) higher than the median income in their residential neighborhood. Moreover, once this residential location effect is controlled, the average life satisfaction is almost 0.5 point greater if respondents' household income is over $\mathrm{HK} \$ 3,000$ higher than the duration-weighted average of the median incomes in the neighborhoods where they have undertaken activities on the day of the survey.

These findings suggest that relative income effects on life satisfaction consist of two geographical components. There is both a structural, more static component linked to people's neighbors and a more dynamic element associated with daily encounters at places where people spend time. At least for the current sample, the neighbor component is more important than that for daily encounters. In fact, once absolute household income is added 
to the model specification (Model C), the time use related element becomes statistically insignificant whereas the residential location component is hardly affected.

At the same time, social comparison effects of income on life satisfaction seem to be asymmetrical: while downward comparison appears to make respondents more satisfied with life, the estimated coefficients in Models B-C for earning at least HK\$3,000 less than the neighborhood where they live or spend time are not consistent with the notion that upward comparison has a (negative) influence on life satisfaction. Model C does reinforce the earlier point that relative income is correlated more strongly with life satisfaction than the reference and absolute income are. Compared to Model A, the effect of a respondent's absolute household income is diminished by a factor three. With 0.45 point in Model C, the effect of household income is approximately one-third of the combined effect of earning over $\mathrm{HK} \$ 3,000$ more or less than the median income in the residential neighborhood and other places where activities have been undertaken on the survey day. ${ }^{3}$

Apart from the income variables, two other neighborhood variables are significantly $(p<0.10)$ associated with life satisfaction. Life satisfaction is greater among respondents living in neighborhoods where the proportion of highly educated people is higher (Models B-C) and where the majority of dwellings belongs to the public rental sector (Model A). The latter result may be a proxy for greater life satisfaction in areas where income inequalities are lower (see also Cheung and Lucas, 2016; Ala-Mantila et al., 2018). Neither

\footnotetext{
${ }^{3}$ When all relevant coefficients are considered irrespective of statistical significance level, the total combined effect is $0.39+0.71+0+0.36=+1.46$ point.
} 
population density nor accessibility is significantly related with life satisfaction, which is perhaps surprising in light of the significant attention to the relationship between degree of urbanization and wellbeing in recent literature.

As for life circumstances, Table 4 shows that life satisfaction is higher if respondents own a car and are married but lower among men and those who are employed. The finding for employment status echoes that of our previous study in Beijing (Wang and Wang, 2015) but differs from studies in the Western context (e.g. White et al., 2013; Okulicz-Kozaryn and Mazelis, 2018). The number of social contacts is positively correlated with life satisfaction, which is consistent with previous studies of the link between social capital and life satisfaction (e.g. Lyubomirsky et al., 2005; Okulicz-Kozaryn and Mazelis, 2018).

\subsubsection{Emotional wellbeing during daily activities}

To answer the question of whether the pleasure experienced depends on income comparison in places that are visited as part of daily activities, we have estimated logistic regression models with activity episode valence as the dependent variable. As mentioned earlier, activity episode valence is measured on a seven-point scale from 1 (very unpleasant) to 7 (very pleasant). To reduce the complexity of the modeling task, we have recoded this variable into a dummy variable with ' 1 ' representing scores from 5 to 7 and ' 0 ' representing other scores (1 to 4). Independent variables include activity episode attributes, characteristics of neighborhoods where activities are conducted and life circumstances, as 
well as relative income - here defined as the difference between respondent's household income and the median household income of the neighborhood where the concerned activities are conducted. As in the life satisfaction models, two dummy variables are defined: if respondents' monthly household income is more than $\mathrm{HK} \$ 3,000$ higher or lower than the median household income of the activity neighborhood, respectively. The set of variables for life circumstances is identical to that deployed in the life satisfaction models discussed above. Because individual respondents may have reported multiple activity episodes of a particular category for the survey day, the assumption of statistically independent observations that undergirds logistic regression modeling may be violated. To avoid this problem and obtain valid tests for the statistical significance of parameter estimates, we have adopted the clustered robust standard errors estimation method. This method provides robust estimates and is widely used to account for serial correlations between observations (e.g. Williams, 2000; Petersen, 2009). Four models have been developed for in-home, work, maintenance and recreation activities, respectively (Table 5). Though not uncommon for this kind of analysis, the models have rather low pseudo Rsquare values.

[Insert Table 5 and Figure 3 here]

Overall, Table 5 and Figure 3 suggest that the social comparison effects of income extend beyond life satisfaction to emotional wellbeing at the activity episode level. The relative income variables are statistically significant $(p<0.10)$ in three of the four models. Respondents derive greater pleasure from in-home and work activities if their household 
income is considerably higher than the median income in the neighborhood where they reside or work. As with life satisfaction, the relative income effect is asymmetrical. This is because the level of pleasure derived from in-home or work activities does not differ significantly between respondents with a household income that is at least UK\$3,000 lower than the neighborhood median and those with income that are broadly in line with the neighborhood median.

The effects of relative income for shopping and other maintenance activities and for recreation are qualitatively different from those for in-home or work activities. While respondents do seem to derive some pleasure from undertaking shopping and other maintenance activities in locations where the median income is substantially lower than their own, this effect is not statistically significant at $p<0.10$. More importantly, engaging in shopping and other maintenance activities in richer neighborhoods (relative to respondents' household income) may increase the level of pleasure associated with such activities. This finding seems to be reasonable because richer neighborhoods are more likely to have a better shopping environment. The relative income variables do not generate statistically significant $(p<0.10)$ differences in the model for recreation activities, primarily because of the small sample size and possibly also because more pleasure is derived from recreation activities than from other kinds of activity (Figure 3). The estimated probabilities are nonetheless consistent with a small diminishing effect of upward social comparison on pleasure derived from recreation activities. 
As for the other activity neighborhood attributes, the percentage of people living and working in the same district is positively correlated with pleasure derived from work and recreation activities. In other words, the emotional wellbeing from working and recreation episodes is greater in areas with higher levels of self-containment. This is understandable because such areas are often full of opportunities for diverse activities and thus offer plenty of choices for people. Pleasure at work is more likely if people are working in a neighborhood with more highly educated people, implying that it is more pleasurable to work in neighborhoods of higher socio-cultural class than in that of lower socio-cultural class. This finding is consistent with the effect of relative income on work activities, and supports the importance of social comparisons regarding relative income matter to people's wellbeing. On the other hand, the opposite effect is found for emotional wellbeing associated with maintenance activities: shopping and running errands in neighborhoods with many inhabitants belonging to the higher socio-cultural classes is less likely to be enjoyable. This finding also echoes that concerning the effects of relative income on the momentary wellbeing of shopping activities, which could be because of better shopping environments in richer neighborhoods. Finally, there is some evidence that is consistent with recent studies finding an inverse relationship between degree of urbanization and life satisfaction (e.g. Okulicz-Kozaryn, 2015, 2017), albeit only for recreation activities. Respondents are less likely to enjoy such activities as accessibility from activity locations is greater, which is probably because of the problems associated with high-accessibility areas, such as crowding, congestion, pollution, noise, dirt and perceptions of higher levels of crime. 
Differences in pleasure derived from daily activities according to activity attributes and life circumstances depend quite strongly on the type of activity. The most consistent differences are that activities, in particular at home or for maintenance purposes, are more likely to be undertaken jointly with others and by women.

\section{Conclusions and Discussion}

This study intended to answer two questions: how is people's life satisfaction affected by living and spending time in neighborhoods where the income is different from their own? Will people experience more (less) pleasure when they frequent places as part of daily urban life where they are better (worse) off than the average others? Results from the multivariate analyses of empirical data collected in Hong Kong show that our answer to both questions is largely affirmative.

Four main conclusions can be drawn from the analysis. First, the relative income variables were more strongly correlated with life satisfaction than the absolute and reference income indicators. This can be interpreted as clear evidence that social comparisons regarding income matter to people's satisfaction with life in the Hong Kong sample considered in this study. Second, the geographical dimension of relative income is not restricted to people's residential neighborhood. Social comparisons with regard to income also occur as part of daily encounters during people's activities in different parts of the city and seems to affect satisfaction with life. The analysis suggests that the effects on life satisfaction of 
income comparison with residential neighbors were stronger than those during daily activities for the sample considered. Nonetheless, the results indicate that the effects of geographical context need to be specified correctly in research on the relationship between income and wellbeing in order to minimize the UGCoP (Kwan, 2012), particularly if highresolution spatial data are used.

Third, the importance of relative income and social comparison extends beyond life satisfaction to emotional wellbeing at the activity episode level, even though - as might be expected (Kahneman et al. 2006; Kahneman and Deaton, 2010) - the effects were weaker than for life satisfaction. Still, the relative income variables were also statistically significantly linked to the pleasure derived from in-home, work and shopping activities. Working and conducting in-home activities in poorer neighborhoods when compared to individuals' own income was more likely to be enjoyed than conducting those activities in richer neighborhoods. In contrast, shopping and errands in richer neighborhoods were more likely to be pleasurable than those in poorer neighborhoods.

Finally, irrespective of what aspect of wellbeing was considered, the statistical effects of relative income and social comparison were asymmetrical and non-linear. Downward comparison seems to trigger greater differences in life satisfaction and pleasure derived from in-home and work activities than upward comparison, although the opposite appears to hold for pleasure from shopping and errands. In all cases, the effects of relative income and comparison became evident once a threshold - a difference of $\mathrm{HK} \$ 3,000$ in this study - was crossed. The findings imply that the specification of relative income effects in 
econometric models of variations in subjective wellbeing should allow for non-linearity in effects.

In short, our study in Hong Kong has confirmed the social comparison effect of income on wellbeing not only with regard to the residential neighborhood - as many previous studies have suggested (see Section 2.3.2) - but also in relation to other sites in the city where people are exposed to income situations as part of their daily activities. The implication is that the impact of social comparison in the science of happiness needs to be theorized as dynamic, mobile and contingent upon people's daily trajectories through time and space. Taking such a time-geographical perspective (Hägerstrand, 1970; Ellegård, 2018) also helps to understand why comparison with neighbors may be more important than with others and sites encountered over the course of daily activities. People's dwelling is after all the site to which they return at the end of most days. It is the base or anchor location around which everyday life is organized and structured, often for considerable periods of time. Comparison with neighbors may therefore obtain a depth that comparison with people in other geographical context lacks. Nonetheless, our analysis suggests that places beyond the residential neighborhood cannot be ignored in understanding how social comparison mediates the relationship between income and wellbeing.

Two further theoretical implications can be identified. The study confirms and extends the earlier findings that social comparison effects with regard to income are relevant to variations in subjective wellbeing in the Chinese context (Knight et al., 2009; Asadullah et al., 2018). The study also adds credence to the argument that upward comparison in 
particular places may make people not only miserable because of "a feeling of lower relative income" but also happier because of access to better or aspirational "local public goods" (Clark et al., 2009, page 525). These counteracting effects can both exert influence on individuals' subjectively experienced wellbeing. How they interact and combine can differ across population groups, in part because they are distributed differently across urban space (see Albor et al., 2014), but also across people's time use and activity participation. For our sample the local public goods income argument seems to be germane to the pleasure derived from shopping and errands, while the feeling of relative poverty might be slightly more important when time was spent at home or on recreation (although the corresponding coefficients for in-home and recreation activities in Table 5 were not significant at $p<0.10)$.

For policy makers, the social comparison effects of income on wellbeing may have implications for policies to establish greater social mixing in urban neighborhoods. Such policies are popular means to mitigate the negative externalities of residential segregation on the basis of income or other factors but they rarely meet expectations (e.g. Bolt et al., 2010). If replicated in other cities and urban contexts, our ceteris paribus finding that downward income comparisons with one's neighbors increase happiness while upward comparison affects happiness much less could be mobilized in attempts to make living in mixed incomes more attractive to different income groups in the city. It should be clear, however, that this is a short-term measure to enhance social mixing. In the long term reducing income inequality across different population groups can help both to increase social mixing and to improve overall life satisfaction of all urban residents. Moreover, the 
positive effect of upward income comparison on the pleasure derived from shopping and errands in locations where people are richer than oneself raises questions about the often subtle attempts and techniques to exclude lower-income groups from urban retail complexes in order to retain the exclusivity and attractiveness of those complexes to highend consumers (see Zukin et al., 2016).

This study has multiple limitations that should be addressed in future research. Not only is a larger and fully representative sample desirable, the inclusion of additional geographical context variables such as land use, provision of specific facilities (parks, stores, etc.) and detailed housing characteristics would also be helpful. In addition, this study relied on administrative delimitations of neighborhoods but these often do not coincide with people's understandings and perceptions of neighborhoods. The use of existing administrative spatial units also makes the study vulnerable to the 'modifiable areal unit problem' (MAUP) (Openshaw and Taylor, 1979); the MAUP's implications should be considered in future research. In addition, it would be useful to explore whether the associations between relative income and wellbeing are identical across different social groups and across neighborhoods that differ in terms of income inequality or social capital (see also Yeung and Lucas, 2016). Furthermore, the identification of geographical reference groups can be refined. Neighbors have been defined only in terms of physical closeness but could also be defined on the basis of people's ego-centric social networks in their residential area. This is particularly attractive in light of the argument that the impact of relative income on wellbeing may be stronger for those who interact more with their neighbors (Clark and Senik, 2010). People encountered as part of daily activities can be identified not only in 
terms of who live in the sites where activities are undertaken but also who is present there at the same time as the individuals whose wellbeing is examined. Big data from smartphones could be utilized to identify such dynamically co-located populations.

Despite these limitations, the current paper has demonstrated the importance of carefully specifying the geographical dimensions of relative income in studies of subjective wellbeing and of paying due attention to the dynamic and mobile nature of social comparison in the science of happiness.

\section{References}

Aknin L B, Norton M I and Dunn E W (2009) From wealth to well-being? Money matters, but less than people think. The Journal of Positive Psychology, 4(6): 523527.

Ala-Mantila S, Heinonen J, Junnila S and Saarsalmi P (2018) Spatial nature of urban well-being. Regional Studies, 52(7): 959-973.

Albor C, Uphoff E P, Stafford M, Ballas D, Wilkinson R G and Pickett K E (2014). The effects of socioeconomic incongruity in the neighbourhood on social support, selfesteem and mental health in England. Social Science \& Medicine, 111: 1-9.

Arifwidodo S and Perera R (2011) Quality of life and compact development policies in Bandung, Indonesia. Applied Research in Quality of Life, 6(2): 159-179. 
Aslam A and Corrado L (2012) The geography of well-being. Journal of Economic Geography, 12(3): 627-649.

Asadullah M N, Xiao S and Yeoh E (2018) Subjective well-being in China, 2005-2010: the role of relative income, gender, and location. China Economic Review, 48: 83101.

Ballas D (2013) What makes a 'happy city'? City, 32(S1), S39-S50.

Ballas D and Tranmer M (2012) Happy people or happy places? A multilevel modeling approach to the analysis of happiness and well-being. International Regional Science Review, 35(1): 70-102.

Berry B J L and Okulicz-Kozaryn A (2011) An urban-rural happiness gradient. Urban Geography, 32(6): 871-883

Birenboim A (2018) The influence of urban environments on our subjective momentary experiences. Environment and Planning B: Urban Analytics and City Science, 45(5): 915-932.

Bolt D, Phillips D and Van Kempen R (2010) Housing policy, (de)segregation and social mixing: an international perspective. Housing Studies, 25(2): 129-135.

Boyce C J, Brown G D A and Moore S C (2010) Money and happiness: rank of income, not income, affects life satisfaction. Psychological Science, 21(4): 471-475.

Caporale G M, Georgellis Y, Tsitsianis N and Yin Y P (2009) Income and happiness across Europe: Do reference values matter? Journal of Economic Psychology, 30(1): $42-51$.

Chen J, Davis D S, Wu K and Dai H (2015) Life satisfaction in urbanizing China: the effect of city size and pathways to urban residency. Cities, 49: 88-97. 
Cheng Z, Wang H and Smyth R (2013) Happiness and job satisfaction in urban China: a comparative study of two generations of migrants and urban locals. Urban Studies, 51(10): 2160-2184.

Cheung F and Lucas R E (2016) Income inequality is associated with stronger social comparison effects: The effect of relative income on life satisfaction. Journal of Personality and Social Psychology, 110(2): 332-341.

Clark A E, Frijters P and Shields M A (2008). Relative income, happiness, and utility: an explanation for the Easterlin paradox and other puzzles. Journal of Economic Literature, 46(1), 95-144.

Clark A E, Westergård-Nielsen N and Nicolai Kristensen N (2009) Economic satisfaction and income rank in small neighbourhoods. Journal of the European Economic Association, 7(2/3): 519-527.

Clark A E and Senik C (2010) Who compares to whom? The anatomy of income comparisons in Europe. The Economic Journal, 120(544): 573-594.

CSDHK (Census and Statistics Department, Hong Kong SAR Government) (2011) Hong Kong Annual Digest of Statistics, 2011 ed. http://www.statistics.gov.hk/pub/B10100032011AN11B0100.pdf (accessed 23.03.16).

Cummins R (2000) Personal income and subjective well-being: a review. Journal of Happiness Studies, 1(2): 133-158.

DeLang, C. O. and Lung, H. C. (2010). Public housing and poverty concentration in urban neighbourhoods: The case of Hong Kong in the 1990s. Urban studies, 47(7), 1391-1413. 
Diener E (2000) Subjective well-being: the science of happiness and a proposal for a national index. American Psychologist, Vol 55(1): 34-43.

Diener E, Sandvik E, Seidlitz L and Diener M (1993) The relationship between income and subjective well-being: relative or absolute? Social Indicators Research, 28(3): 195-223.

Dittmann J and Goebel J (2010) Your house, your car, your education: the socioeconomic situation of the neighborhood and its impact on life satisfaction in Germany. Social Indicators Research, 96(3): 497-513.

Dong H and Qin B (2017). Exploring the link between neighborhood environment and mental wellbeing: a case study in Beijing, China. Landscape and Urban Planning, $164,71-80$.

Easterlin R A (1995) Will raising the incomes of all increase the happiness of all? Journal of Economic Behavior \& Organization, 27(1): 35-47.

Ellegård K (2018) Thinking Time Geography: Concepts, Methods and Applications. Routledge, London.

Festinger L (1954) A theory of social comparison processes. Human Relations, 7: 117140.

Florida R, Mellander C and Rentfrow P J (2013) The happiness of cities. Regional Studies, 47(4): 613-627.

Frank R H (2008) Should public policy respond to positional externalities? Journal of Public Economics, 92(8-9): 1777-1786.

Goethals G R, and Klein W M (2000) Interpreting and inventing social reality: Attributional and constructive elements in social comparison. In Suls J and 
Wheeler L (Eds) The Handbook of Social Comparison: Theory and Research, pp 23-44. Plenum, New York.

Gokdemir O and Dumludag D (2012) Life satisfaction among Turkish and Moroccan immigrants in the Netherlands: the role of absolute and relative income. Social Indicators Research, 106(3): 407-417.

Guo Y, Chang S S, Sha F, and Yip P S. (2018). Poverty concentration in an affluent city: Geographic variation and correlates of neighborhood poverty rates in Hong Kong. PloS one, 13(2), e0190566.Hågerstrand T (1970) What about people in regional science? Papers in Regional Science, 24(1): 7-24.

Hagerty M R (2000) Social comparisons of income in one's community: evidence from national surveys of income and happiness. Journal of Personality and Social Psychology, 78(4): 764-771.

Helliwell J F, Huang H and Wang S (2016) Chapter 2: the distribution of world happiness. In: Helliwell J F, Layard R and Sachs J (Eds) World Happiness Report 2016, Update (Vol 1), pp 8-49. Sustainable Development Solutions Network, New York.

Huang J, Wu S and Deng S (2016) Relative income, relative assets, and happiness in urban China. Social Indicators Research, 126(3): 971-985.

Jebb A T, Tay L, Diener E and Oishi S (2018) Happiness, income satiation and turning points around the world. Nature Human Behaviour, 2(1): 33-38.

Jiang S, Lu M and Sato H (2012). Identity, inequality, and happiness: evidence from urban China. World Development, 40(6): 1190-1200. 
Kahneman D and Deaton A (2010) High income improves evaluation of life but not emotional well-being. Proceedings of the National Academy of Sciences, 107(38): 16489-16493.

Kahneman D, Krueger A B, Schkade D, Schwarz N and Stone A A (2006) Would you be happier if you were richer? A focusing illusion. Science, 312(5782): 1908-1910.

Knight J and Gunatilaka R (2010) Great expectations? The subjective well-being of rural-urban migrants in China. World Development, 38(1): 113-124.

Knight J, Song L and Gunatilaka R (2009) Subjective well-being and its determinants in rural China. China Economic Review, 30(4): 635-649.

Kwan M-P (2012) The uncertain geographic context problem. Annals of the Association of American Geographers, 102(5): 958-968.

Latif E (2016) Happiness and comparison income: evidence from Canada. Social Indicators Research, 128(1):161-177.

Lee W H, Ambrey C and Pojania D (2018) How do sprawl and inequality affect wellbeing in American cities? Cities, 79: 70-77.

Lenzi C and Perucca G (2018) Are urbanized areas source of life satisfaction? Evidence from EU regions. Papers in Regional Science, 97(S1): S105-S122.

Li N P and Kanazawa S (2016) Country roads, take me home... to my friends: how intelligence, population density, and friendship affect modern happiness. British Journal of Psychology, 107(4): 675-697.

Liu Y, Zhang F, Wu F, Liu Y and Li Z (2017) The subjective wellbeing of migrants in Guangzhou, China: The impacts of the social and physical environment. Cities, 60: $333-342$. 
Ludwig J, Duncan G J, Gennetian L A, Katz L F, Kessler R C, Kling J R and Sanbonmatsu L (2012) Neighborhood effects on the long-term well-being of lowincome adults. Science, 337(6101): 1505-1510.

Luttmer E F P (2005) Neighbors as negatives: relative earnings and well-being. The Quarterly Journal of Economics, 120(3): 963-1002.

Lyubomirsky S, Sheldon K M and Schkade D (2005) Pursuing happiness: the architecture of sustainable change. Review of General Psychology, 9(2): 111-131.

Ma J, Dong G, Chen Y and Zhang W, (2018) Does satisfactory neighbourhood environment lead to a satisfying life? An investigation of the association between neighbourhood environment and life satisfaction in Beijing. Cities, 74: 229-239.

MacKerron G and Mourato S (2009) Life satisfaction and air quality in London. Ecological Economics, 68(5): 1441-1453.

Monkkonen P., and Zhang X. (2011). Socio economic segregation in Hong Kong: Spatial and ordinal measures in a high density and highly unequal city. Working Paper 2011-03, Institute of Urban and Regional Development, University of California.

Morrison P S (2011) Local expressions of subjective well-being: the New Zealand experience. Regional Studies, 45(8): 1039-1058.

Nordbakke S and Schwanen T (2014) Well-being and mobility: a theoretical framework and literature review focusing on older people. Mobilities, 9(1): 104-129.

Oishi S, Kesebir S and Diener E (2011) Income inequality and happiness. Psychological Science, 22(9): 1095-1100. 
Okulicz-Kozaryn A (2015). Happiness and Place: Why Life is Better Outside of the City. Palgrave Macmillan, New York.

Okulicz-Kozaryn A (2017) Unhappy metropolis (when American city is too big). Cities, 61: 144-155.

Okulicz-Kozaryn A and Mazelis J M (2018) Urbanism and happiness: a test of Wirth's theory of urban life. Urban Studies, 55(2): 349-364.

Openshaw S and Taylor P J (1979) A million or so correlation coefficients: three experiments on the modifiable areal unit problem. In: Wrigley N (Ed) Statistical Applications in Spatial Sciences, pp 127-144. Pion, London.

Oswald A J and Wu S (2010) Objective confirmation of subjective measures of human well-being: Evidence from the U.S.A. Science, 327(5965): 576-579.

Pacione M (2003) Urban environmental quality and human wellbeing — a social geographical perspective. Landscape and Urban Planning, 65(1-2): 19-30.

Parducci A (1968) The relativism of absolute judgments. Scientific American, 219(6): 8490.

Petersen M A (2009) Estimating standard errors in finance panel data sets: comparing approaches. Review of Financial Studies, 22(1): 435-480.

Schönfelder S and Axhausen K W (2003). Activity spaces: measures of social exclusion? Transport Policy, 10(4): 273-286.

Schwanen T and Wang D (2014) Well-being, context, and everyday activities in space and time. Annals of American Association of Geographers, 104(4): 833-851.

Sun S, Chen J, Johannesson M, Kind P and Burström K (2016). Subjective well-being and its association with subjective health status, age, sex, region, and socio- 
economic characteristics in a Chinese population study. Journal of Happiness Studies, 17(2), 833-873.

Thompson C W, Roe J, Aspinall P A, Mitchell R, Clow A, and Miller D (2012) More green space is linked to less stress in deprived communities: Evidence from salivary cortisol patterns. Landscape and Urban Planning, 105 (3): 221-229.

Veenhoven R and Hagerty M (2006) Rising happiness in nations 1946-2004: A reply to Easterlin. Social Indicators Research, 79(3): 421-436.

Wang D and Wang F (2015) Contributions of the usage and affective experience of the residential environment to residential satisfaction. Housing Studies, 31(1): 42-60.

Wang F and Wang D (2016) Geography of urban life satisfaction: An empirical study of Beijing. Travel Behaviour and Society, 5: 14-22

Wang D, Li F, and Chai Y (2012) Activity space: a new perspective of socio-spatial segregation in Beijing, China. Urban Geography, 33(2): 256-277.

Wen M and Wang G (2009). Demographic, psychological, and social environmental factors of loneliness and satisfaction among rural-to-urban migrants in Shanghai, China. International Journal of Comparative Sociology, 50(2): 155-182.

White M P, Alcock I, Wheeler B W and Depledge M H (2013) Would you be happier living in a greener urban area? A fixed-effects analysis of panel data. Psychological Science, 24(6): 920-928.

Williams R L (2000) A note on robust variance estimation for cluster-correlated data. Biometrics, 56(2): 645-646.

Wills, T. (1981) Downward comparison principles in social psychology. Psychological Bulletin, 90(2): 245-271. 
Wu X and Li J (2017). Income inequality, economic growth, and subjective well-being: Evidence from China. Research in Social Stratification and Mobility, 52: 49-58. Zhang Z and Zhang J (2017). Perceived residential environment of neighborhood and subjective well-being among the elderly in China: A mediating role of sense of community. Journal of Environmental Psychology, 51, 82-94.

Zukin S, Kasinitz P and Chen X (Eds) (2016) Global Cities, Local Streets: Everyday Diversity from New York to Shanghai. Routledge, New York. 
Table 1: Life satisfaction versus income difference* (in HK\$, $1 \mathrm{HK} \$=0.13 \mathrm{US} \$$ )

\begin{tabular}{|c|c|c|c|c|c|c|c|c|}
\hline & & Life satisfaction & $\begin{array}{l}\text { Not at all } \\
\text { Satisfied }\end{array}$ & $\begin{array}{r}\text { Not } \\
\text { Satisfied }\end{array}$ & Neutral & Satisfied & $\begin{array}{r}\text { Very } \\
\text { satisfied }\end{array}$ & All \\
\hline \multirow{2}{*}{\multicolumn{2}{|c|}{$\begin{array}{l}\text { The entire } \\
\text { sample }\end{array}$}} & Mean difference\# & $-6,919$ & $-4,292$ & 3,279 & 10,359 & 17,506 & 6,872 \\
\hline & & Cases $(\%)$ & $\begin{array}{r}11 \\
(1.4)\end{array}$ & $\begin{array}{r}57 \\
(7.4)\end{array}$ & $\begin{array}{r}297 \\
(38.6)\end{array}$ & $\begin{array}{r}343 \\
(44.5)\end{array}$ & $\begin{array}{r}62 \\
(8.0)\end{array}$ & $\begin{array}{r}770 \\
(100)\end{array}$ \\
\hline \multirow{4}{*}{$\begin{array}{l}\text { Gen- } \\
\text { der }\end{array}$} & \multirow{2}{*}{$\begin{array}{l}\text { Femal } \\
\mathrm{e}\end{array}$} & Mean difference\# & $-7,871$ & $-5,615$ & 1,336 & 8,121 & 18,638 & 5,267 \\
\hline & & Cases $(\%)$ & $\begin{array}{r}5 \\
(1.1)\end{array}$ & $\begin{array}{r}31 \\
(6.9)\end{array}$ & $\begin{array}{r}167 \\
(37.2)\end{array}$ & $\begin{array}{r}212 \\
(47.2)\end{array}$ & $\begin{array}{r}34 \\
(7.6)\end{array}$ & $\begin{array}{r}449 \\
(100)\end{array}$ \\
\hline & \multirow[t]{2}{*}{ Male } & Mean difference\# & $-6,125$ & $-2,715$ & 5,776 & 13,982 & 16,131 & 9,118 \\
\hline & & Cases $(\%)$ & $\begin{array}{r}6 \\
(1.9)\end{array}$ & $\begin{array}{r}26 \\
(8.1)\end{array}$ & $\begin{array}{r}130 \\
(40.5)\end{array}$ & $\begin{array}{r}131 \\
(40.8)\end{array}$ & $\begin{array}{r}28 \\
(8.7)\end{array}$ & $\begin{array}{r}321 \\
(100)\end{array}$ \\
\hline \multirow[t]{6}{*}{ Age } & \multirow[t]{2}{*}{$<30$} & Mean difference\# & $-2,647$ & -3860 & 530 & 1,984 & -533 & 616 \\
\hline & & Cases $(\%)$ & $\begin{array}{r}7 \\
(1.9)\end{array}$ & $\begin{array}{r}35 \\
(9.4)\end{array}$ & $\begin{array}{r}150 \\
(40.2)\end{array}$ & $\begin{array}{r}159 \\
(42.6)\end{array}$ & $\begin{array}{r}22 \\
(5.9)\end{array}$ & $\begin{array}{r}373 \\
(100)\end{array}$ \\
\hline & \multirow[t]{2}{*}{$30-50$} & Mean difference\# & $-14,394$ & $-4,319$ & 7,183 & 19,379 & 22,734 & 12,900 \\
\hline & & Cases $(\%)$ & $\begin{array}{r}4 \\
(1.4)\end{array}$ & $\begin{array}{r}20 \\
(7.1)\end{array}$ & $\begin{array}{r}107 \\
(37.8)\end{array}$ & $\begin{array}{r}128 \\
(45.2)\end{array}$ & $\begin{array}{r}24 \\
(8.5)\end{array}$ & $\begin{array}{r}283 \\
(100)\end{array}$ \\
\hline & \multirow[t]{2}{*}{$>50$} & Mean difference\# & -- & $-11,580$ & 3,145 & 13,522 & 34,467 & 12,380 \\
\hline & & Cases $(\%)$ & -- & $\begin{array}{r}2 \\
(1.7)\end{array}$ & $\begin{array}{r}40 \\
(35.1)\end{array}$ & $\begin{array}{r}56 \\
(49.1)\end{array}$ & $\begin{array}{r}16 \\
(14)\end{array}$ & $\begin{array}{r}114 \\
(100)\end{array}$ \\
\hline
\end{tabular}

* income difference refers to the difference between a respondent's monthly household income and the median monthly household income of the respondent's home sub-district (in HK\$)

\# mean difference is the mean of the income differences of all respondents in the respective category 
Table 2: Life satisfaction versus income difference* (in HK\$)

\begin{tabular}{l|crr}
\hline & & \multicolumn{3}{c}{ Mean income difference\# in } \\
Life satisfaction & $\mathrm{N}(\%)$ & Entire activity space & Out-of-home activity space \\
\hline Not at all satisfied & $11(1.4)$ & -7794 & -3358 \\
Not satisfied & $57(7.4)$ & -4430 & -6354 \\
Neutral & $297(38.6)$ & 3039 & 1725 \\
Satisfied & $343(44.5)$ & 10340 & 9863 \\
Very satisfied & $62(8.0)$ & 18613 & 18541 \\
Total & $770(100)$ & 6837 & 6033 \\
\hline * income difference refers to the differences between respondents' monthly household income and the time duration weighted \\
average median household income of the districts covered by activity space & & \\
\# mean income difference is the mean of the income differences of all respondents in the respective category.
\end{tabular}


Table 3: Valence dimension versus income difference* (in HK\$)

\begin{tabular}{l|cccccccc}
\hline \multirow{2}{*}{ Valence } & \multicolumn{2}{|c}{ In-home activities } & \multicolumn{2}{c}{ Work activities } & \multicolumn{2}{c}{ Shopping activities } & \multicolumn{2}{c}{ Recreation activities } \\
& Mean\# & $\mathrm{N}$ & Mean\# & $\mathrm{N}$ & Mean\# & $\mathrm{N}$ & Mean\# & $\mathrm{N}$ \\
\hline 1 (very unpleasant) & 10,713 & 17 & 8,103 & 20 & $-13,892$ & 4 & $-18,171$ & 1 \\
2 & 430 & 27 & $-1,221$ & 32 & 14,281 & 6 & 18,331 & 6 \\
\hline 3 & 1,843 & 97 & $-1,784$ & 75 & 3,273 & 30 & $-24,282$ & 5 \\
\hline 5 & 2,738 & 564 & 1,304 & 185 & $-3,597$ & 111 & $-4,588$ & 35 \\
\hline 6 & 6,992 & 874 & 7,767 & 226 & 5,963 & 198 & 5,700 & 61 \\
7 (very pleasant) & 9,005 & 862 & 7,728 & 136 & 7,688 & 182 & 5,711 & 118 \\
\hline Total & 7,347 & 825 & 3,360 & 65 & 6,522 & 156 & -299 & 133 \\
\hline
\end{tabular}

* income difference refers to the differences between respondents' monthly household income and the median household income of the neighborhood where the activity is conducted

\# mean income difference is the mean of the income differences of all respondents in the respective category. 
Table 4: Unstandardized coefficients in ordered logit model for life satisfaction

\begin{tabular}{|c|c|c|c|}
\hline Variables & $\begin{array}{l}\text { Model A } \\
\text { Reference } \\
\text { income \& } \\
\text { Absolute income }\end{array}$ & $\begin{array}{l}\text { Model B } \\
\text { Relative income } \\
\text { only }\end{array}$ & $\begin{array}{l}\text { Model C } \\
\text { Relative income } \\
\text { \& Absolute } \\
\text { income }\end{array}$ \\
\hline $\begin{array}{l}\text { Life circumstances } \\
\text { Gender }(\text { female }=0)\end{array}$ & & & \\
\hline $\begin{array}{l}\text { Male } \\
\text { Age }(30-50=0)\end{array}$ & -0.241 & $-0.267 *$ & $-0.268^{*}$ \\
\hline $\begin{array}{l}<30 \\
>50\end{array}$ & $\begin{array}{l}0.134 \\
0.365\end{array}$ & $\begin{array}{l}0.135 \\
0.348\end{array}$ & $\begin{array}{l}0.163 \\
0.343\end{array}$ \\
\hline Marital status $($ non-married $=0)$ & & & \\
\hline $\begin{array}{l}\text { Married } \\
\text { A driver's license }(\mathrm{no}=0)\end{array}$ & $0.469^{* *}$ & $0.490^{* *}$ & $0.483^{* *}$ \\
\hline $\begin{array}{l}\text { Yes } \\
\text { Education Attainment (other }=0 \text { ) }\end{array}$ & -0.225 & -0.258 & -0.252 \\
\hline $\begin{array}{l}\text { Secondary school or lower } \\
\text { Postgraduate or higher }\end{array}$ & $\begin{array}{c}0.382^{* *} \\
0.042\end{array}$ & $\begin{array}{c}0.384 * * \\
0.145\end{array}$ & $\begin{array}{l}0.407 * * \\
0.077\end{array}$ \\
\hline $\begin{array}{l}\text { Employment status (non-employed }=0 \text { ) } \\
\text { Employed }\end{array}$ & $-0.562 * * *$ & $-0.643 * * *$ & $-0.635 * * *$ \\
\hline $\begin{array}{l}\text { Monthly household income }(\text { other }=0) \\
<\mathrm{HK} \$ 20,000 \\
>\mathrm{HK} \$ 40,000\end{array}$ & $\begin{array}{l}-0.646 * * * \\
0.902 * * *\end{array}$ & & $\begin{array}{l}0.163 \\
0.446^{*}\end{array}$ \\
\hline $\begin{array}{l}\text { Housing type (other }=0) \\
\text { Public rental housing } \\
\text { Ownership of private cars }(\mathrm{no}=0)\end{array}$ & -0.219 & -0.261 & -0.236 \\
\hline $\begin{array}{l}\text { Yes } \\
\text { Household size }\end{array}$ & $\begin{array}{l}0.512 * * \\
-0.008\end{array}$ & $\begin{array}{l}0.512 * * \\
-0.019\end{array}$ & $\begin{array}{c}0.466^{* *} \\
-0.028\end{array}$ \\
\hline $\begin{array}{l}\text { Children aged }<12 \text { in household }(\mathrm{no}=0) \\
\text { Yes }\end{array}$ & -0.208 & -0.155 & -0.196 \\
\hline $\begin{array}{l}\text { Older adults aged } \geq 65 \text { in household }(\mathrm{no}=0) \\
\text { Yes } \\
\text { Weekly number of social contacts through all means }\end{array}$ & $\begin{array}{l}-0.126 \\
0.005^{*}\end{array}$ & $\begin{array}{l}-0.074 \\
0.005^{*}\end{array}$ & $\begin{array}{l}-0.049 \\
0.005^{*}\end{array}$ \\
\hline Home neighborhood factors & & & \\
\hline Neighborhood accessibility & -0.037 & -0.034 & -0.038 \\
\hline Population density & $8.319 \mathrm{E}-008$ & $3.068 \mathrm{E}-007$ & $2.385 \mathrm{E}-007$ \\
\hline $\begin{array}{l}\text { Presence of public rental housing }(0<x<50=0) \\
\text { No } \\
\geq 50 \text { percent }\end{array}$ & $\begin{array}{c}0.032 \\
0.423^{*}\end{array}$ & $\begin{array}{l}0.006 \\
0.292\end{array}$ & $\begin{array}{l}0.017 \\
0.323\end{array}$ \\
\hline $\begin{array}{l}\text { Percentage of older adults aged } \geq 65 \text { (other }=0 \text { ) } \\
\leq 10 \text { percent } \\
\geq 15 \text { percent }\end{array}$ & $\begin{array}{l}0.007 \\
0.025\end{array}$ & $\begin{array}{r}-0.033 \\
0.014\end{array}$ & $\begin{array}{c}-0.022 \\
0.012\end{array}$ \\
\hline $\begin{array}{l}\text { Percentage of people with tertiary education or } \\
\text { higher }\end{array}$ & 1.729 & $2.820^{* *}$ & $2.706^{* *}$ \\
\hline Percentage of people working in the same district & -0.224 & -0.481 & -0.458 \\
\hline Median monthly household income & $-8.447 \mathrm{E}-006$ & & \\
\hline $\begin{array}{l}\text { Respondent's monthly household income is (other }=0 \text { ) } \\
\text { over HK } \$ 3000 \text { less than neighborhood median } \\
\text { over HK } \$ 3000 \text { more than neighborhood median } \\
\text { Respondent's monthly household income is (other }=0 \text { ) }\end{array}$ & & $\begin{array}{c}-0.324 \\
0.790 * * *\end{array}$ & $\begin{array}{c}-0.390 \\
0.712 * * *\end{array}$ \\
\hline $\begin{array}{l}\text { over HK\$3000 less than the mean of neighborhood } \\
\text { medians\# }\end{array}$ & & 0.135 & 0.097 \\
\hline
\end{tabular}




\begin{tabular}{|c|c|c|c|}
\hline $\begin{array}{l}\text { over HK } \$ 3000 \text { more than the mean of } \\
\text { neighborhood medians\# }\end{array}$ & & $0.446^{*}$ & 0.357 \\
\hline \multicolumn{4}{|l|}{ Model fit } \\
\hline -2 Log Likelihood & 1699.0 & 1688.3 & 1683.3 \\
\hline Chi-Square & 124.3 & 135.0 & 139.7 \\
\hline Degree of freedom & 25 & 26 & 28 \\
\hline Pseudo $R^{2}$ (McFadden) & 0.068 & 0.074 & 0.077 \\
\hline
\end{tabular}

\# 'The mean of neighborhood medians' refers to the mean of the median household income of neighborhoods where out-of-home activities are conducted, weighted by the time duration spent in the neighborhoods;

$* p<0.1, * * p<0.05, * * * p<0.01$ 
Table 5: Unstandardized coefficients in logistic regression models for episode wellbeing

\begin{tabular}{|c|c|c|c|c|}
\hline & $\begin{array}{l}\text { In-home } \\
\text { activities }\end{array}$ & $\begin{array}{c}\text { Work } \\
\text { activities }\end{array}$ & $\begin{array}{l}\text { Shopping } \\
\text { activities }\end{array}$ & $\begin{array}{c}\text { Recreation } \\
\text { activities }\end{array}$ \\
\hline \multicolumn{5}{|l|}{ Activity episode attributes } \\
\hline $\begin{array}{l}\text { Time of day }(6 \mathrm{pm}-6 \mathrm{am}=0) \\
6 \mathrm{am}-11 \mathrm{am} \\
11 \mathrm{am}-3 \mathrm{pm}\end{array}$ & $\begin{array}{l}-0.135 \\
-0.159\end{array}$ & $\begin{array}{l}0.140 \\
0.289\end{array}$ & $\begin{array}{c}-0.711 * * \\
0.028\end{array}$ & $\begin{array}{l}-0.301 \\
0.081\end{array}$ \\
\hline $3 \mathrm{pm}-6 \mathrm{pm}$ & -0.101 & -0.006 & -0.397 & -0.037 \\
\hline $\begin{array}{l}\text { Duration }(>120 \mathrm{~min}=0) \\
<30 \mathrm{~min} \\
30-60 \mathrm{~min}\end{array}$ & $\begin{array}{c}0.245 \\
0.226^{*}\end{array}$ & $\begin{array}{c}0.000 \\
-0.294\end{array}$ & $\begin{array}{c}-1.249 * * * \\
-0.290\end{array}$ & $\begin{array}{l}-2.952 * * * \\
-0.437\end{array}$ \\
\hline $60-120 \mathrm{~min}$ & -0.141 & 0.339 & -0.119 & 0.325 \\
\hline $\begin{array}{l}\text { Company }(\text { With others }=0) \\
\text { Alone } \\
\text { Life circumstances }\end{array}$ & $-0.303 * *$ & -0.064 & $-0.664 * *$ & -0.251 \\
\hline $\begin{array}{l}\text { Gender }(\text { female }=0) \\
\text { Male } \\
\text { Age }(\text { aged } 30-50=0)\end{array}$ & $-0.339 * *$ & $-0.407 * *$ & -0.302 & -0.409 \\
\hline $\begin{array}{l}\text { Aged }<30 \\
\text { Aged }>50\end{array}$ & $\begin{array}{l}-0.144 \\
0.143\end{array}$ & $\begin{array}{l}0.222 \\
0.379\end{array}$ & $\begin{array}{l}-0.117 \\
-0.329\end{array}$ & $\begin{array}{l}0.339 \\
0.049\end{array}$ \\
\hline $\begin{array}{l}\text { Education level (other }=0 \text { ) } \\
\text { Secondary school or lower } \\
\text { Postgraduate or higher }\end{array}$ & $\begin{array}{l}-0.030 \\
-0.160\end{array}$ & $\begin{array}{l}0.293 \\
0.287\end{array}$ & $\begin{array}{c}-0.078 \\
0.441\end{array}$ & $\begin{array}{c}0.361 \\
-0.667\end{array}$ \\
\hline $\begin{array}{l}\text { Employment status }(\mathrm{no}=0) \\
\text { Employed } \\
\text { Monthly household income }(\text { other }=0)\end{array}$ & 0.194 & -0.212 & 0.049 & -0.168 \\
\hline$<\mathrm{HK} \$ 20,000$ & $0.570 *$ & -0.059 & -0.159 & 0.092 \\
\hline$>\mathrm{HK} \$ 40,000$ & 0.175 & 0.132 & 0.627 & 0.685 \\
\hline \multicolumn{5}{|l|}{ Housing type (other $=0)$} \\
\hline Public rental housing & -0.006 & 0.163 & 0.097 & -0.597 \\
\hline Household size & 0.108 & -0.107 & $0.245 * *$ & -0.053 \\
\hline \multicolumn{5}{|l|}{ Marital status (non-married=0) } \\
\hline Married & 0.307 & $0.477^{*}$ & $1.025 * * *$ & -0.485 \\
\hline \multicolumn{5}{|l|}{ Driver's license $(\mathrm{no}=0)$} \\
\hline Yes & -0.250 & 0.047 & -0.260 & -0.182 \\
\hline \multicolumn{5}{|l|}{ Ownership of private cars $(\mathrm{no}=0)$} \\
\hline Yes & 0.345 & 0.208 & 0.158 & 0.512 \\
\hline \multicolumn{5}{|l|}{ Children aged $<12$ in household $(\mathrm{no}=0)$} \\
\hline Yes & 0.083 & $0.557 * *$ & $-0.973 * * *$ & $1.222^{*}$ \\
\hline \multicolumn{5}{|l|}{ Older adults aged $\geq 65$ in household $(\mathrm{no}=0)$} \\
\hline Yes & -0.116 & 0.160 & -0.142 & -0.789 \\
\hline $\begin{array}{l}\text { Weekly number of social contacts through all } \\
\text { means } \\
\text { Activity neighborhood factors }\end{array}$ & -0.002 & -0.002 & -0.006 & 0.001 \\
\hline Accessibility & -0.062 & 0.057 & 0.247 & $-0.666^{* *}$ \\
\hline Percentage of public rental housing & 0.064 & 0.566 & 0.119 & 1.182 \\
\hline
\end{tabular}




\begin{tabular}{|c|c|c|c|c|}
\hline Percentage of older adults $(\geq 65)$ & -2.194 & -3.888 & -2.446 & -0.313 \\
\hline $\begin{array}{l}\text { Percentage of people with at least tertiary } \\
\text { education }\end{array}$ & 1.241 & $3.052 * *$ & $-4.410 * *$ & 2.273 \\
\hline Percentage of people working in the same district & 0.505 & $2.262 * *$ & 0.925 & $5.767 * *$ \\
\hline \multicolumn{5}{|l|}{ Respondent's household income is (other $=0$ ) } \\
\hline $\begin{array}{l}\text { Over HK } \$ 3,000 \text { less than the neighborhood } \\
\text { median }\end{array}$ & -0.222 & 0.151 & $0.825 * *$ & -0.671 \\
\hline $\begin{array}{l}\text { Over HK } \$ 3,000 \text { more than the neighborhood } \\
\text { median }\end{array}$ & $0.557 * *$ & $0.659^{* *}$ & 0.436 & -0.352 \\
\hline Constant & 0.734 & -1.168 & 1.203 & 2.895 \\
\hline $\mathrm{N}$ & 3266 & 732 & 687 & 359 \\
\hline \multicolumn{5}{|l|}{ Model fit } \\
\hline-2 log likelihood & 3258.6 & 935.8 & 651.1 & 238.1 \\
\hline LR Chi-Square & 148.59 & 69.79 & 74.42 & 40.67 \\
\hline Degree of freedom & 31 & 31 & 31 & 31 \\
\hline Pseudo $R^{2}$ (McFadden) & 0.044 & 0.063 & 0.100 & 0.146 \\
\hline
\end{tabular}

$* p<0.1,{ }^{* *} p<0.05, * * * p<0.01$ 


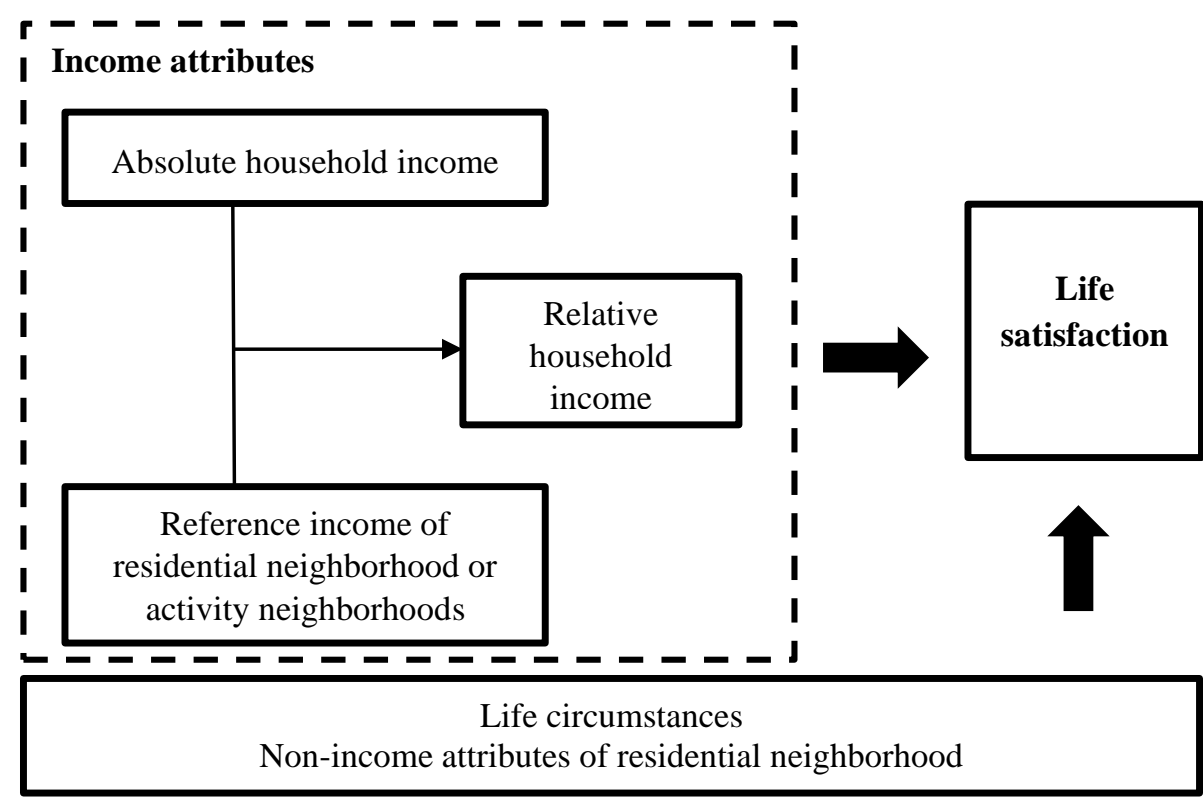

Activity episode attributes

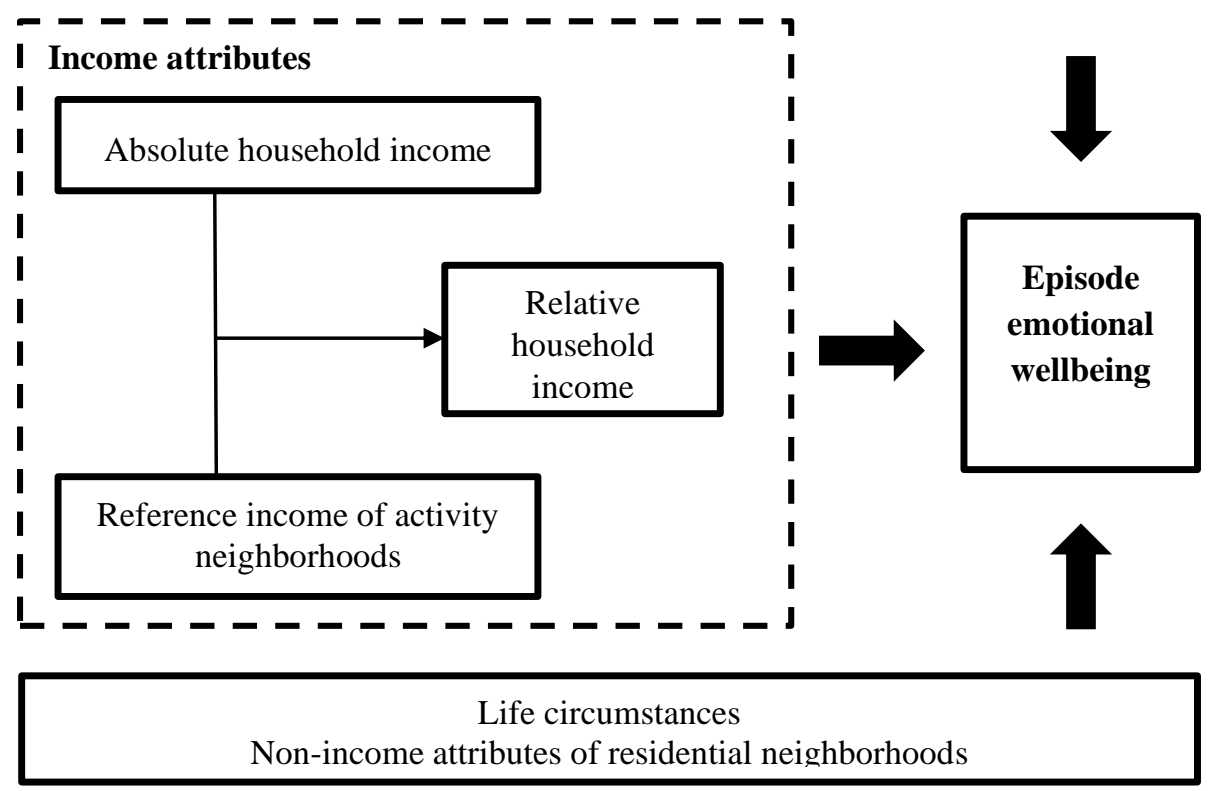

Figure 1. Expected relationships for life satisfaction (top) and episode-level emotional wellbeing (bottom) 


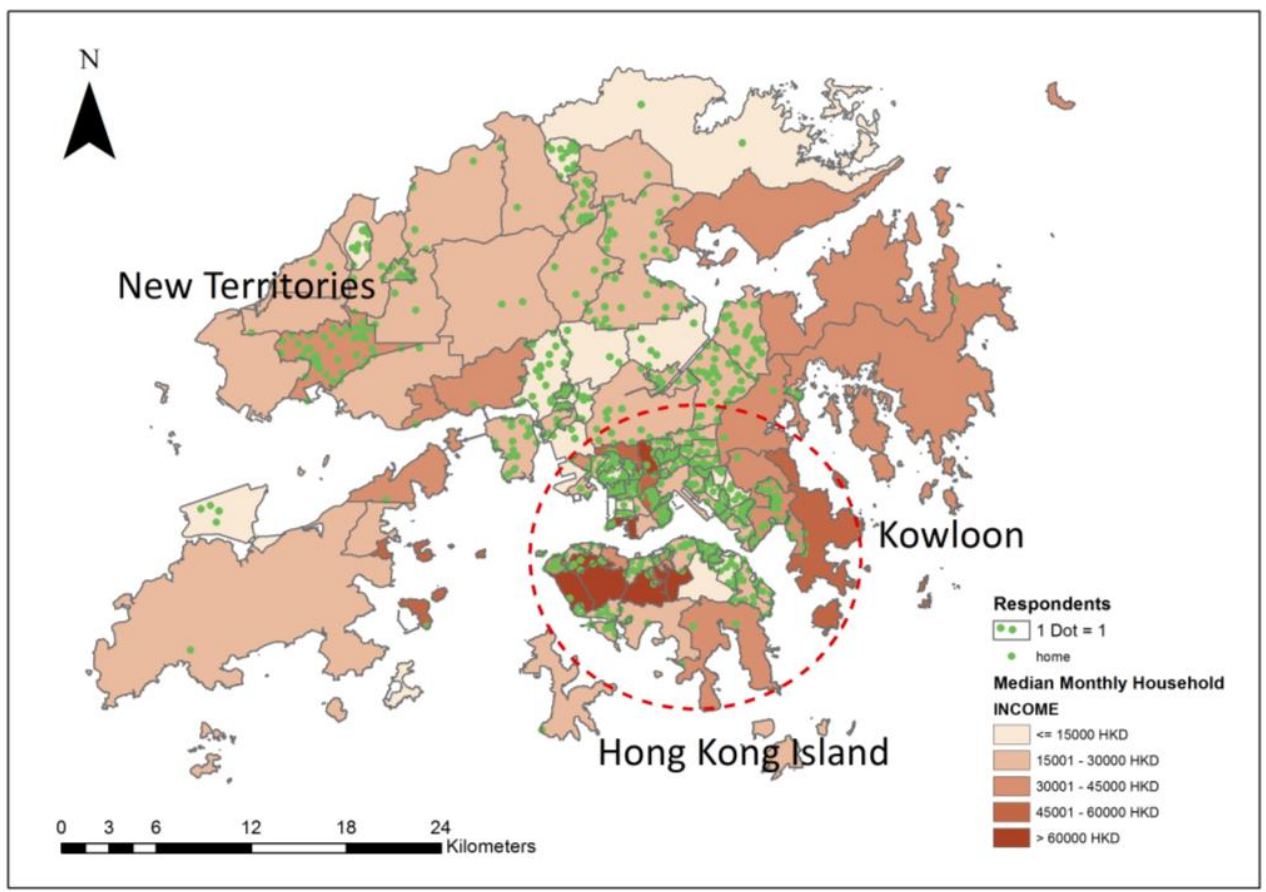

Figure 2: Spatial distribution of respondents against median monthly household income of grouped DCCAs 


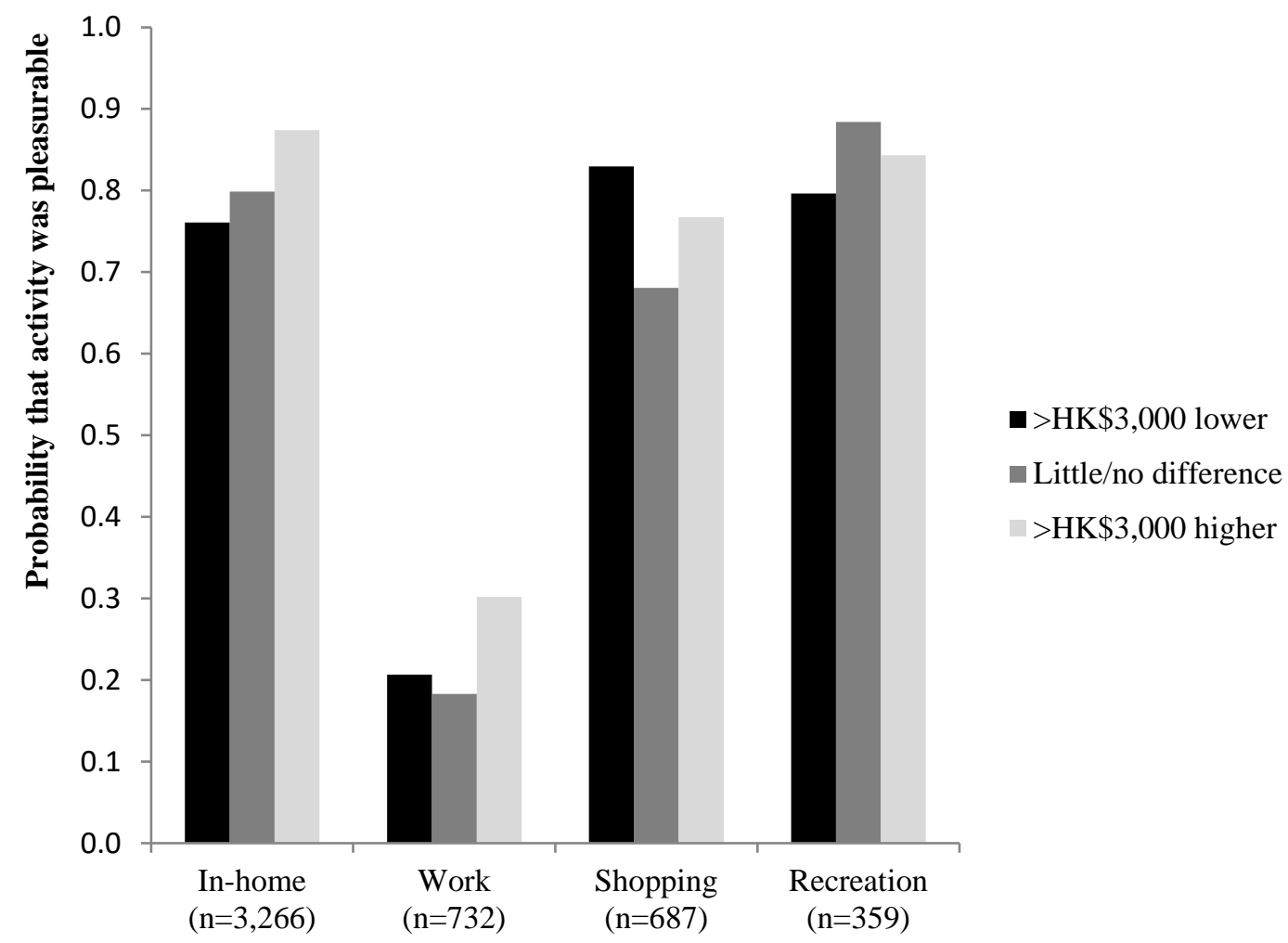

Estimated probabilities for activities lasting at least 120 minutes, started in the afternoon, undertaken together with others and conducted by women aged 30-50, in employment, with medium education and income levels, not living in public rental housing, without a driving license or a car, in a married couple without children or older adult in the households, living in an average Hong Kong neighborhood as far as accessibility, proportion of highly educated and older people and adults living and working in the same neighborhood and public rental housing is concerned.

Figure 3: Estimated probabilities of activity episodes being pleasurable, according to activity type and relative income 